
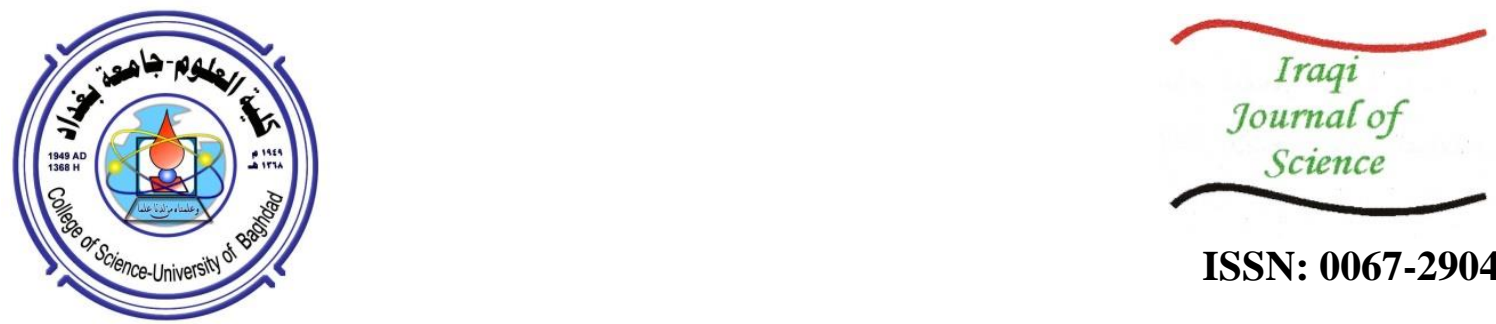

ISSN: 0067-2904

\title{
Identification of Vulnerable Zones for Groundwater Using a GIS-based DRASTIC Technique in Shwan Sub-basin/North-Iraq
}

\author{
Hussein Dheyaa Al-Hayali ${ }^{1}$, Omer S. Ibrahiem Al-Tamimi ${ }^{2}$, Dara Faeq Hamamin ${ }^{3}$ \\ ${ }^{1}$ Department of Geology, College of Science, University of Kirkuk, Kirkuk, Iraq. \\ ${ }^{2}$ Department of Geology, College of Science, University of Sulaiman ,Sulaymaniyah, Iraq.
}

Received: 23/7/2020 Accepted: $21 / 8 / 2020$

\begin{abstract}
Groundwater is considered as one of the most important sources of fresh-water, on which many regions around the world depend, especially in semi-arid and arid regions. Protecting and maintaining groundwater is a difficult process, but it is very important to maintain an important source of water. The current study aims to assess the susceptibility of groundwater to pollution using the DRASTIC model along with the GIS environments and its tool boxes. A vulnerability map was created by relying on data collected from 55 wells surveyed by the researchers as well as archived records from governmental institutions and some international organizations. The results indicate that the region falls into three vulnerability functional zones, namely very low, low and medium. Fortunately, most of the region is in a very low - low range (89-125) which covers approximately $94.6 \%$ of total area of the region, while the medium zone (125-133) forms 5.4\%, as the smallest part of the total area of region. To reduce the risk of pollution in the medium zones of vulnerability, precautionary measures must be taken before commencing industrial or agricultural activities.
\end{abstract}

Keywords: Vulnerability, DRASTIC Model, Inter granular aquifer, Function zoning, Shwan sub-basin.

\section{تحديد انطقة المياه الجوفية الأكثر عرضة للتلوث بأستخدام تقنية (DRASTIC) المستندة الى نظم

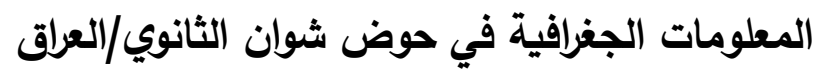

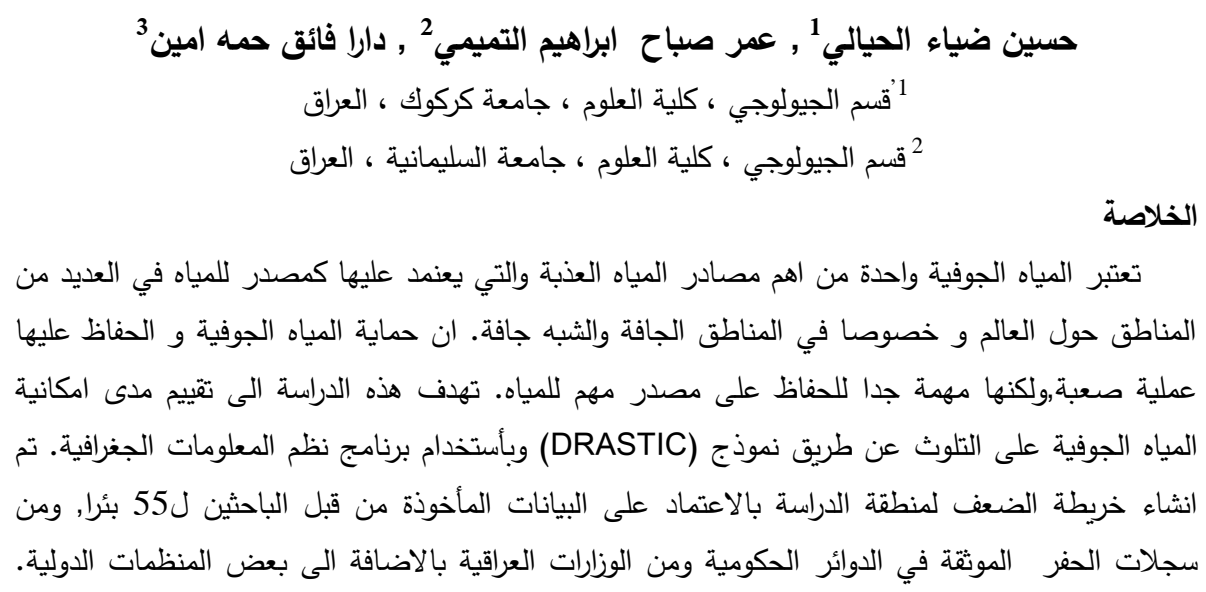

*Email: hussein.hydro92@gmail.com 


$$
\begin{aligned}
& \text { تثير النتائج الى ان المنطقة تقع ضمن ثلاث من انطقة الضعف "المنخفضة جدا , المنخفضة , المتوسطة" . } \\
& \text { لحسن الحظ ان اغلب اجزاء المنطقة تقع ضمن النطاق "المنخفض جدا - منخفض" بين "89-100" بينما } \\
& \text { يشكل النطاق المتوسط للضعف (125-133) جزء صغير جدا من مساحة المنطقة. للحد من مخاطر التلوث } \\
& \text { في مناطق الضعف المتوسطة ، يجب اتخاذ تدابير وقائية قبل البدء في الأنثطة الصناعية أو الزراعية. }
\end{aligned}
$$

\section{Introduction}

The vulnerability map is considered as a valuable tool in environmental management and constitutes an important part of water protection schemes [1]. Many studies described freshwater availability in terms of type, quantity, and quality, which can possibly deteriorate due to the spatial and temporal changes in the water availability [2]. Vulnerability maps are used to determine the area of potential groundwater pollution. To keep the groundwater from pollution, groundwater vulnerability assessment can act as the most helpful and realistic tool $[3,4,5,6,7,8,9]$. Vulnerability is defined as the natural failure to protect groundwater against the risks of pollution due to the local hydrogeological conditions [10]. Margate [11] was the first author to apply the concept of groundwater vulnerability in France in 1968. After that, several methodologies appeared to develop maps of the vulnerability assessment of the aquifer, such as DRASTIC [12], GOD [13], SINTACS [14], AVI" [15], etc.

Shwan sub-basin is located in the North-Eastern part of Iraq, within Kirkuk governorate. It covers an area of about $768 \mathrm{~km}^{2}$. Many commercial industries in addition to agricultural activities occupy large parts of the area of interest, which is shown in Figure 1. The meteorology of the Shwan sub-basin is under the influence of the Mediterranean climate which is described as hot and dry, with long summers as well as cold and wet winters [16].

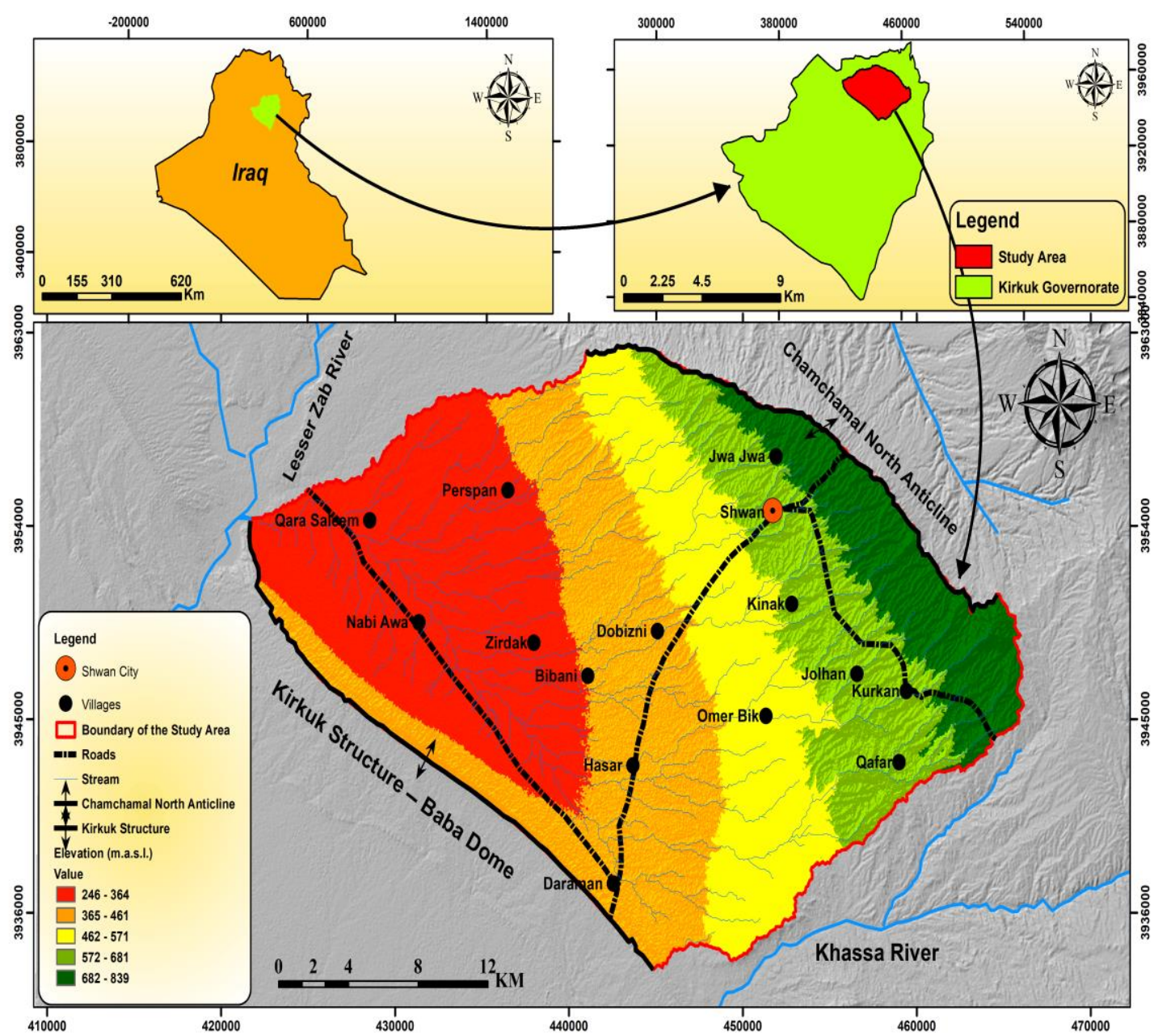

Figure 1- Location and elevation map of the study area. 


\section{Geological setting}

From the geological points of view, the area is situated within the unstable range, specifically in the mountain range [17]. The formations of the Pleistocene to Holocene ages which are represented by Bai-Hassan Formation and the Quaternary deposit are the dominant units exposed in, and surrounding, the basin [18]. The Quaternary deposits in the area of study are separated into Polygenetic and Slope deposits. The area is bordered by Kirkuk structure and Baba Dome from the southwest, Alkassa River from the west, and the Chamchamal anticline from the northeast, as shown in Figure (2).

\section{Hydrogeological setting}

The formations (Bai-Hassan and the Quaternary deposit) are the groups that contain the groundwater aquifers in the study area [18]. The depths of the 55 wells were measured by using GIS program to create the groundwater flow map of the study area, which shows that the water in the area heads mainly from the eastern towards the western directions, as illustrated in Figure (3).

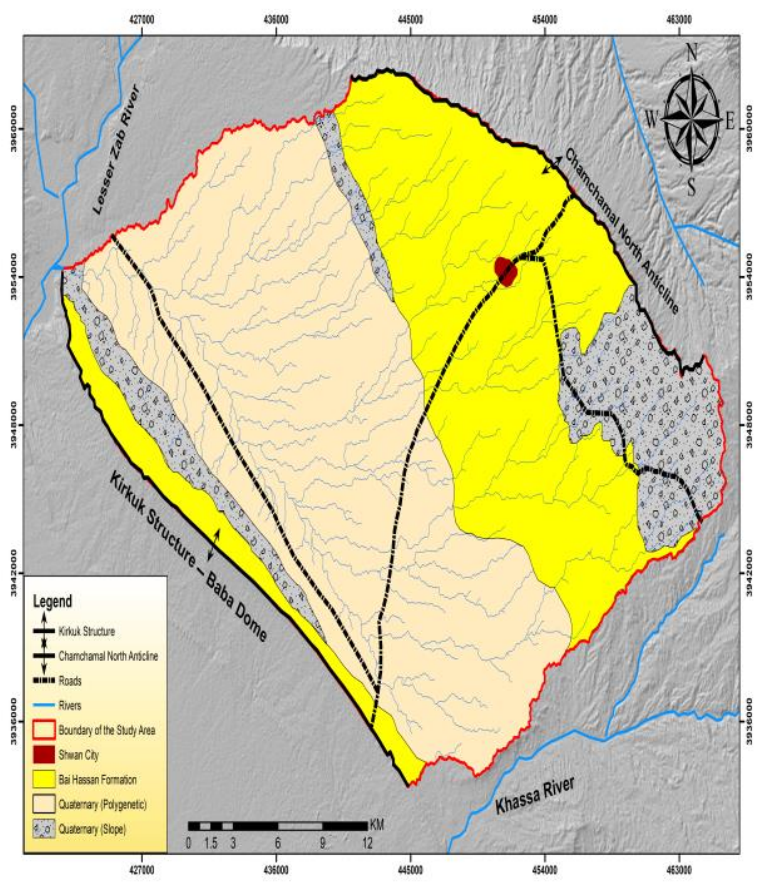

Figure 2- Ge010gical map of the study area

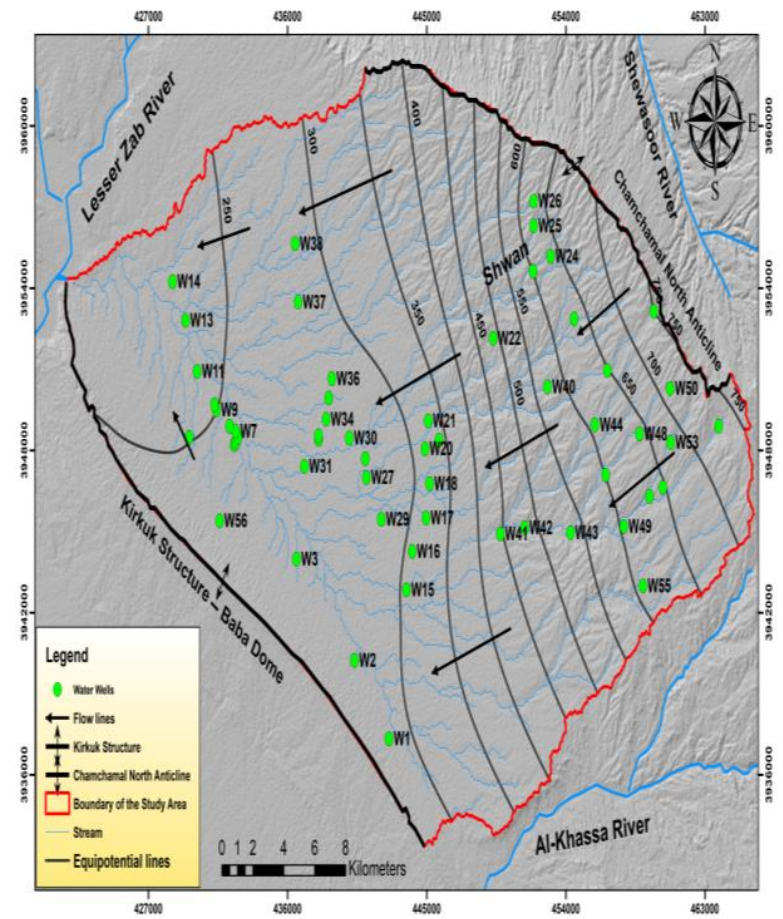

Figure 3- Groundwater flow map of the study area

\section{Materials and methods}

The DRASTIC method is one of the most important and common tools which was developed by EPA (US Environmental Protection Agency) [12] for the purpose of assessing vulnerability in groundwater aquifer. It was subsequently applied by many researchers in many countries who modified it to meet a wide range of different applications, including aquifer thickness, land use, lineaments, and the impact of contaminants [19].

The DRASTIC terminology is the abbreviation of seven parameters, where $\mathrm{D}=\mathrm{Depth}$ to groundwater, $\mathrm{R}=$ Net recharge, $\mathrm{A}=$ Aquifer media, $\mathrm{S}=$ Soil media, $\mathrm{T}=$ Topography, $\mathrm{I}=$ Impact of vadose zone, and $\mathrm{C}=$ Hydraulic conductivity, as shown in Figure 4The DRASTIC technique was originally derived from the rating and weights ass0ciated with the 7 parameters. The seven parameters are divided into a rating that starts from 1 "lowest polluted" to 10 "highest polluted", as demonstrated in Table (1). Also, each parameter has weights which are explained in Table (2). Parameters with ratings and weights were used to calculate the DRASTIC Vulnerability Index (DVI), as follows:

$D V I=\operatorname{Dr} \times D w+\operatorname{Rr} \times \mathbf{R w}+\operatorname{Ar} \times A w+\operatorname{Sr} \times \operatorname{Sw}+\operatorname{Tw} \times \operatorname{Tr}+\operatorname{Ir} \times I w+\operatorname{Cr} \times \mathbf{C w}$ 


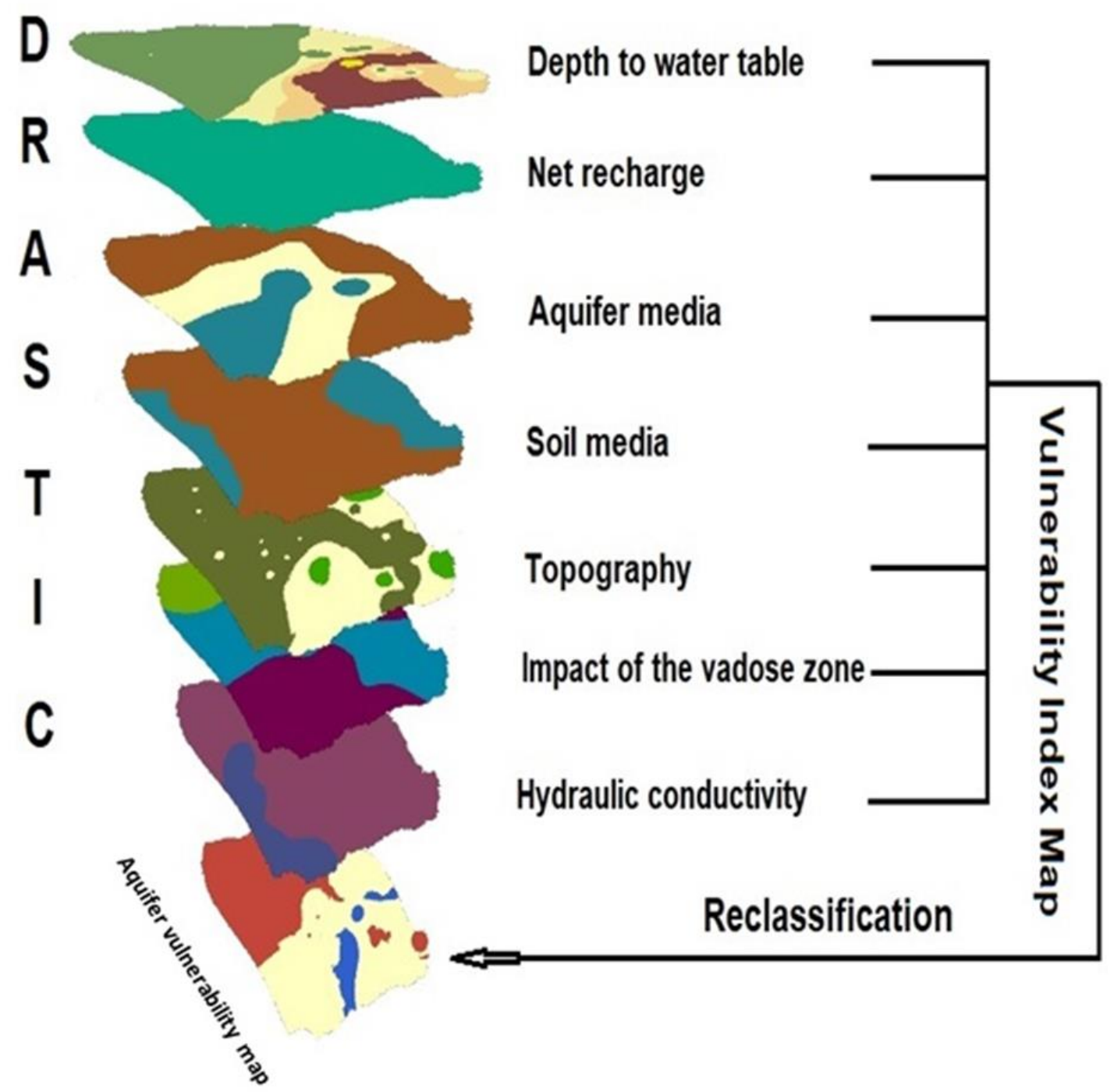

Figure 4- The Methodology flowchart for DRASTIC method

Table 1- Rating of the parameters

\begin{tabular}{|lll|}
\hline Factor & Range & Rating \\
& $0-1.5$ & 10 \\
& $1.5-4.5$ & 9 \\
Depth to & $4.5-9$ & 7 \\
water (m) & $15-22$ & 5 \\
& $22-30$ & 3 \\
& $>30$ & 2 \\
\hline Factor & Range(mm/year & 1 \\
Net & Less than 50 & Rating \\
Recharge & $50-100$ & 1 \\
& $100-175$ & 3 \\
\end{tabular}




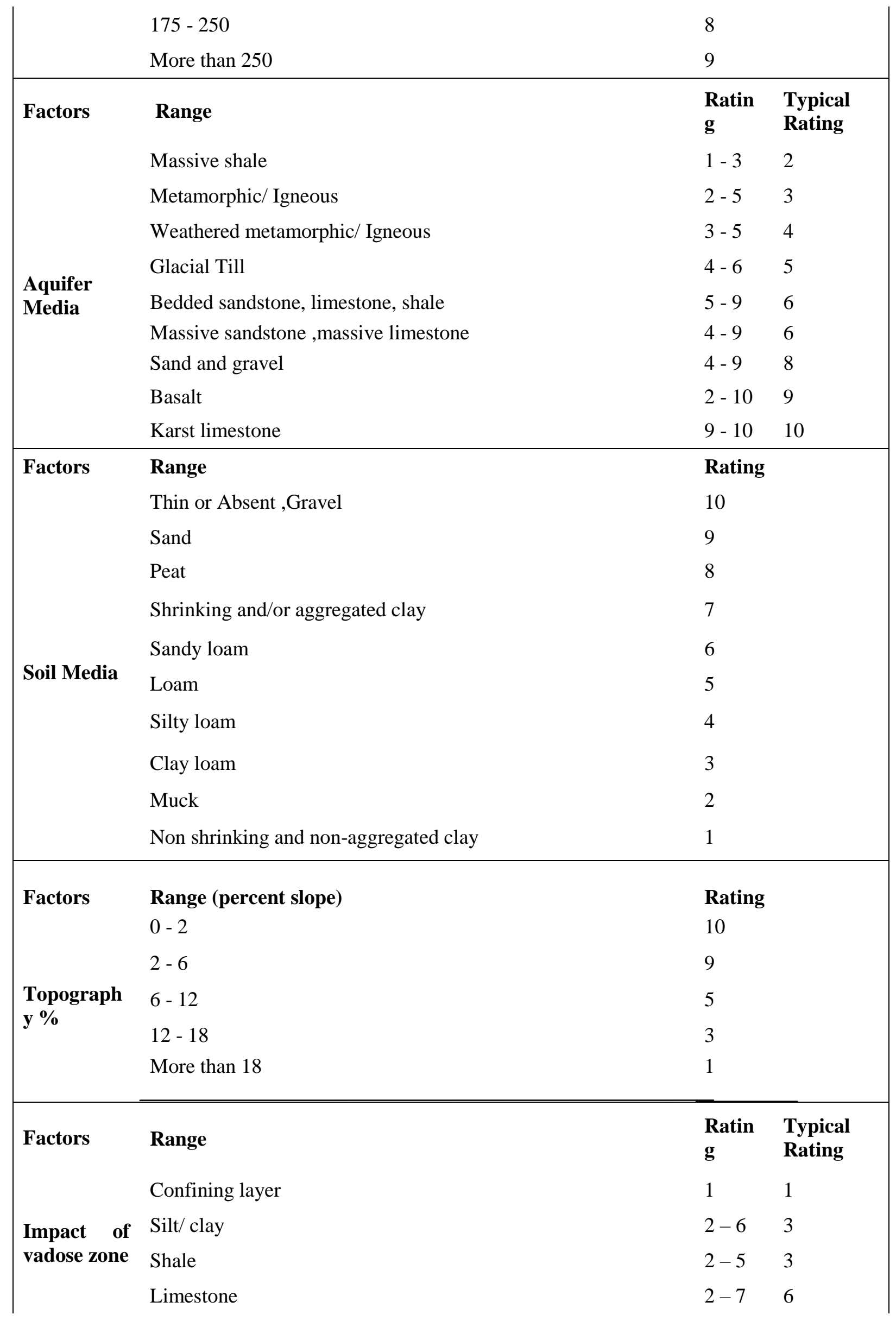




\begin{tabular}{|c|c|c|c|}
\hline & Sandstone, Bedded limestone, sandstone, shale, sand and gravel & $4-8$ & 6 \\
\hline & Metamorphic/ Igneous & $2-8$ & 4 \\
\hline & Sand and gravel & $6-9$ & 8 \\
\hline & Basalt & $2-10$ & 9 \\
\hline & Karst limestone & $8-10$ & 10 \\
\hline \multirow{7}{*}{$\begin{array}{l}\text { Hydraulic } \\
\text { conductivit } \\
\text { y }\end{array}$} & $\mathrm{C}(\mathrm{m} / \mathrm{day})$ & \multicolumn{2}{|l|}{ Rating } \\
\hline & Less than 4.0 & \multicolumn{2}{|l|}{1} \\
\hline & $4.0-12.0$ & \multicolumn{2}{|l|}{2} \\
\hline & $12.0-30.0$ & \multicolumn{2}{|l|}{4} \\
\hline & $30.0-40.0$ & \multicolumn{2}{|l|}{6} \\
\hline & $40.0-80.0$ & \multicolumn{2}{|l|}{8} \\
\hline & More than 80.0 & \multicolumn{2}{|l|}{10} \\
\hline \multicolumn{4}{|c|}{ Table 2- Weights of the parameters } \\
\hline \multicolumn{2}{|l|}{ Factor } & \multicolumn{2}{|l|}{ Weights } \\
\hline \multicolumn{2}{|c|}{ D: Depth to Water } & \multicolumn{2}{|l|}{5} \\
\hline \multicolumn{2}{|c|}{ R: Net Recharge } & \multicolumn{2}{|l|}{4} \\
\hline \multicolumn{2}{|c|}{ A: Aquifer Media } & \multicolumn{2}{|l|}{3} \\
\hline \multicolumn{2}{|c|}{ S: Soil Media } & \multicolumn{2}{|l|}{2} \\
\hline \multicolumn{2}{|c|}{ T: Topography } & \multicolumn{2}{|l|}{1} \\
\hline \multicolumn{2}{|c|}{ I: Impact of the vadose zone } & \multicolumn{2}{|l|}{5} \\
\hline \multicolumn{2}{|c|}{ C: Hydraulic Conductivity } & \multicolumn{2}{|l|}{3} \\
\hline
\end{tabular}

- Depth to water table (D)

Depth to water table is an important factor since it represents the time that the pollutant takes to reach the groundwater level after passing through the unsaturated zone. Shallow water has more chance of contamination; the deeper water has less chance of contamination due to longer arrival time [20]. For the current study, the depth of groundwater was calculated in 55 wells distributed inside the basin. The well data was collected by the researcher in September 2019. The values of this parameter varied greatly from one place to another, ranging from few meters to more than 100 meters below the surface. In general, the rating of D parameter began from 1 "low vulnerability" to 9 "high vulnerability" based on Aller et al. [12], as shown in Figure 5.

\section{- Net Recharge $(\mathbf{R})$}

According to Ersoy et al. [21], net charge is the total quantity of water infiltrating from the surface to an aquifer on an annual basis. Recharge of water is the main way to transfer pollutants vertically to the groundwater and horizontally within the aquifer. Precipitation is the dominant source for recharging groundwater in the area of study. The groundwater net recharge was described by a previous work conducted by Mohammed [22]. Based on his results, the total expected average net recharge was estimated at $62.82 \mathrm{~mm} /$ year or $19.37 \%$ from the total annual precipitation. Accordingly, the recharge value falls within the rating 3 developed by Aller [12] (Figure 6). 


\section{- $\quad$ Aquifer media (A)}

The aquifer medium exerts the major control over the way and path length that a contaminant should follow. The course length is an imp0rtant control, along with permeability and gradient, in the identification of the time available for attenuation processes like sorption, reactivity, and dispersion, in addition to the extension of the effective surface area of materials contacted in the aquifer [12]. The main aquifer in the Shwan sub-basin is represented by the formation of Bai- Hassan and the Quaternary deposits. The saturated thickness of the aquifer was obtained from the drilling records of the Water Drilling Department in Kirkuk Governorate. The thickness of the aquifer in the basin ranges from $34 \mathrm{~m}$ in the village of Hassar to $86 \mathrm{~m}$ in the village of Kinak. The aquifer is mainly composed of sand, gravel, and silt. The northern and eastern parts of the basin are ratified with 7 because this part is the least exposed to pollution. While the southern part has the highest pollution with the rating of 9 , and the middle part has the average rating value of 8 , as demonstrated in Figure (7).

\section{- $\quad$ Soil media (S)}

Soil media refers to the uppermost part of the unsaturated zone. Generally, the soil is the upper weathered zone of the earth. The soil has a remarkable effect on the amount of recharge which can seep through the earth, hence on the capacity of a pollutant to move vertically in the unsaturated zone. In the current study, the soil map for the study area was prepared from the map previously constructed by the Harmonized World Soil Database (HWSD) [23]. The soil map was reclassified to accommodate the classification of the new DRASTIC system. The n0rth-eastern and s0uth-western parts of the basin had a rating of 6 because they fall within the loam range, while the remaining of the basin falls in the rating of 5 because it is situated within the sandy loam, according to Aller [12], (Figure 8).

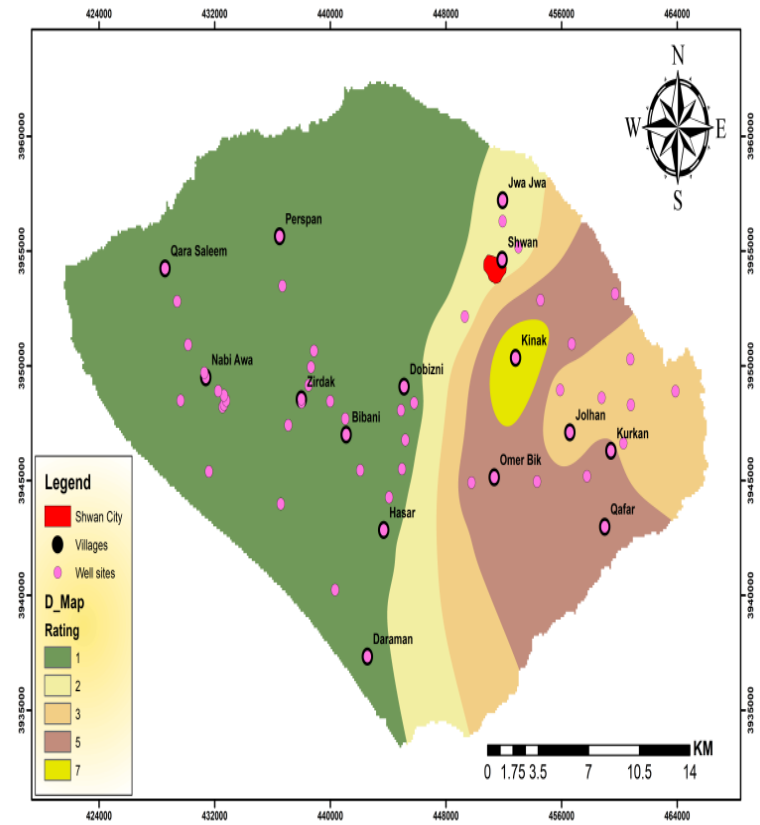

Figure 5- Rating map of depth to groundwater

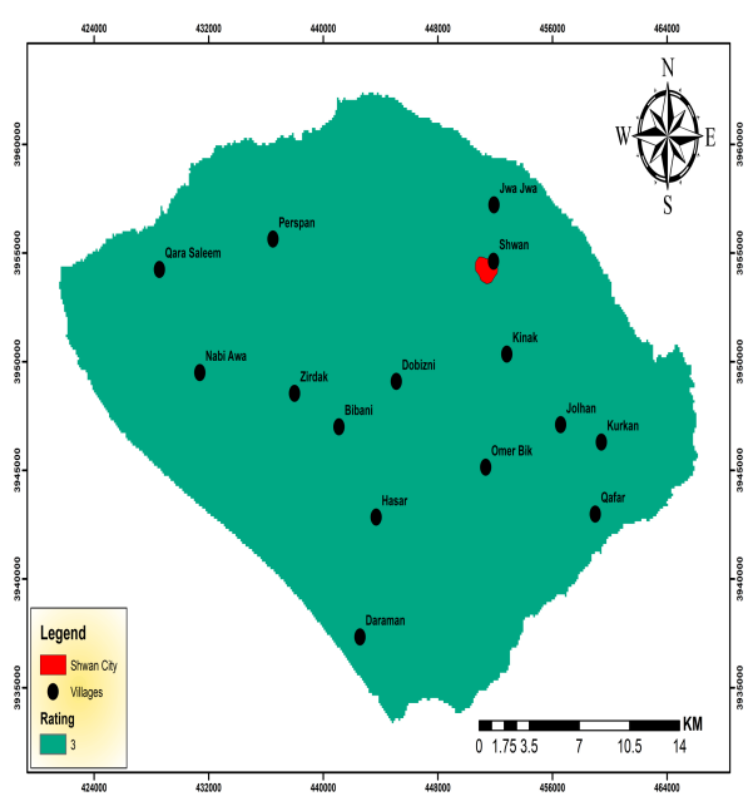

Figure 6- Rating map of net recharge 


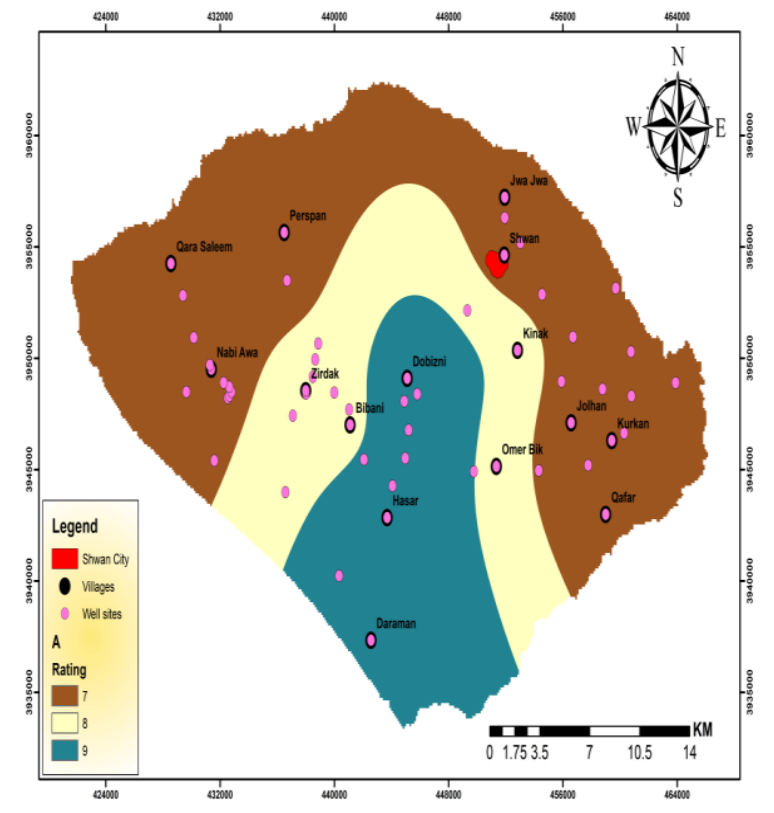

Figure 7- Rating map of aquifer media

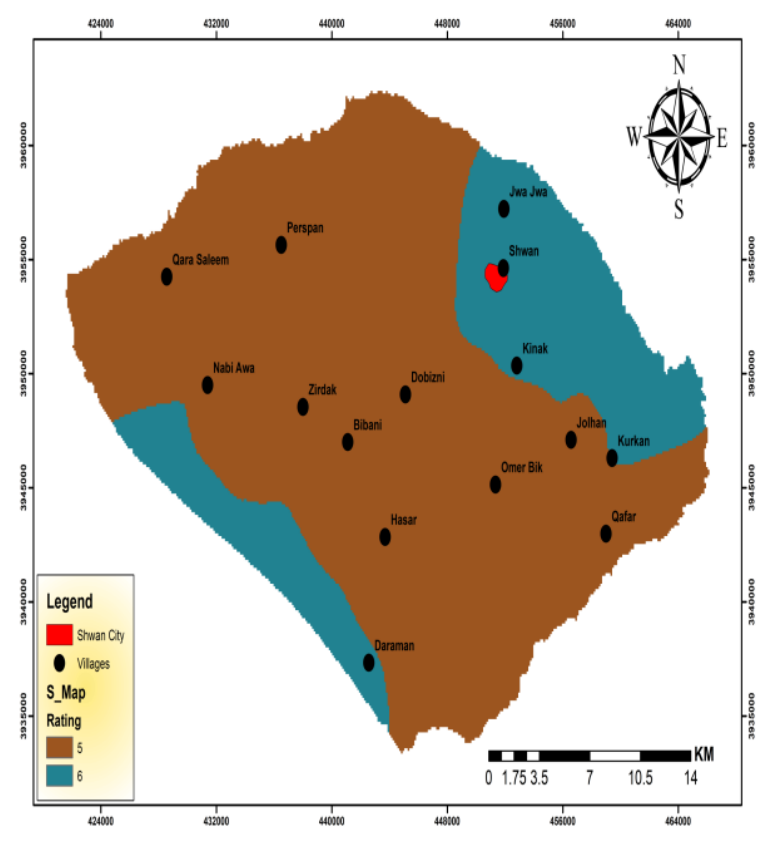

Figure 8- Rating map of soil media

\section{- Topography (T)}

Topography helps in controlling the probability that the contaminant either remains in one area for a long enough time to infiltrate into the ground or runoff to another area. If the slope is less than $2 \%$, the probability of the pollutant to filter into the ground is large because it reduces the amount of surface runoff that exits from the area. If the slope exceeds more than $18 \%$, the probability of pollution decreases due to increased runoff and less filtering [12]. The topography map of the area was prepared through DEM (Digital Elevation Modeling) from NASA with a resolution of $30 \mathrm{~m}$. The slope ranges were extracted from the DEM by the GIS analysis toolbox. The rating values of the topography for most parts of the study area ranged between 9 and 10. In addition, small parts that fall within the regression area had a rating value of 5, as shown in Figure (9).

\section{- Vadose zone impact (I)}

The material attenuation properties of the area above the water table depend on the type of vadose media. The media of the vadose zone controls the length of the path that the pollutant takes before arriving at the water table, thereby affecting the time obtainable for attenuation [12]. In the current study, the rating values for this parameter were determined based on the drilling and profile of well data collected from the Ministry of Water Resources - Wells Drilling Department in Kirkuk Governorate. Based on this archive, the most vulnerable area is located in the western part of the basin. It entirely consists of gravel and therefore rated with 8 . In contrast, the least vulnerable area is located in the northern and central parts of the basin (ratings are 4 and 5, respectively). The other parts of the basin had a rating of 7 due to the fact that they consist mainly of sand and gravel with a less content of silt and clay, as demonstrated in Figure (10).

\section{- Hydraulic conductivity (C)}

This parameter refers to the capacity of the aquifer to transfer water. It also controls the average of the groundwater flow under a given hydraulic gradient. The value of hydraulic conductivity corresponds to the value of the impact of pollutants [24]. Pumping tests, well sketches, and their data were used for the purpose of the assessment of the hydraulic conductivity in the area of interest. Based on the data recorded from 15 drilled water wells, the value of hydraulic conductivity was calculated using the equation:

\section{$\mathbf{K}=\mathbf{T} / \mathbf{b}$;}

where $\mathrm{K}$ is the hydraulic c0nductivity ( $\mathrm{m} /$ day), $\mathrm{T}$ is the transmissivity $\left(\mathrm{m}^{2} /\right.$ day), and $b$ is the saturated thickness (m). The hydraulic c0nductivity ranges for the Shwan sub-basin were reclassified based on the table prepared by Aller [12]. A total number of 6 pumping tests were conducted for the main formations in the area (Bai-Hassan and the Quaternary deposit), while the remaining pumping well 
data were taken from the previously conducted test by Al-Sudani [25]. Accordingly, the values of the hydraulic conductivity for (Bai-Hassan and the Quaternary deposit) ranged 7.31-30 m/day with rating values of 2 and 4 . The southern and south western parts of the basin fell within the rating of 2, while the rest of the basin parts fell into the rating of 4, as shown in Figure (11).

Vulnerability map of the study area

The vulnerability map of the Shwan sub-basin was prepared based on the seven parameters (water depth, net recharge, aquifer media, soil media, topography, impact vadose zone, hydraulic c0nductivity). Seven layers of these parameters were created based on the obtained data from the 55 wells surveyed by the researchers, whereas the archived records were obtained from governmental institutions and some international organizations. These data were treated by using GIS software to produce the seven layers. The final map was created according to the seven layers and reclassified based on Aller [12]. The vulnerability map shows $44.9 \%$ of the area is a very low- vulnerable zone, whereas $49.7 \%$ has a low and $5.4 \%$ a medium-vulnerability, as described in Table (3). The results reveal that the DRASTIC values have a range of 89 - 133. The zonings with very low vulnerability class are located mainly in the western and north-western parts, in addition to small patches in the eastern part of the basin (Figure 12). In contrast, the area with a medium vulnerability zoning occupies a small part of the basin that is located in the south-eastern and eastern parts of the area. The rest of the basin can be classified, however, as having a low pollution, with values having a range of 100-125.

Table 3- Ranges of vulnerability using the DRASTIC model based on Aller et al. [12]

\begin{tabular}{|c|c|c|}
\hline Index of vulnerability & Vulnerability degree & Percentage Area \% \\
\hline Less than 100 & Very low & 44.9 \\
\hline $100-125$ & Low & 49.7 \\
\hline $125-150$ & Medium & 5.4 \\
\hline $150-200$ & High & 0 \\
\hline More than 200 & Very High & 0 \\
\hline
\end{tabular}

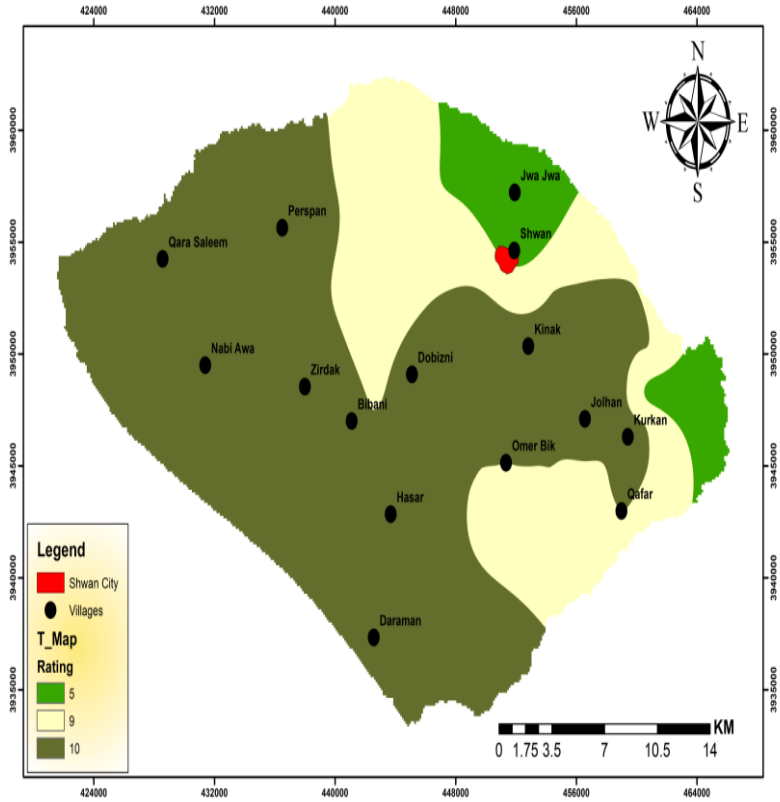

Figure 9- Rating map of topography

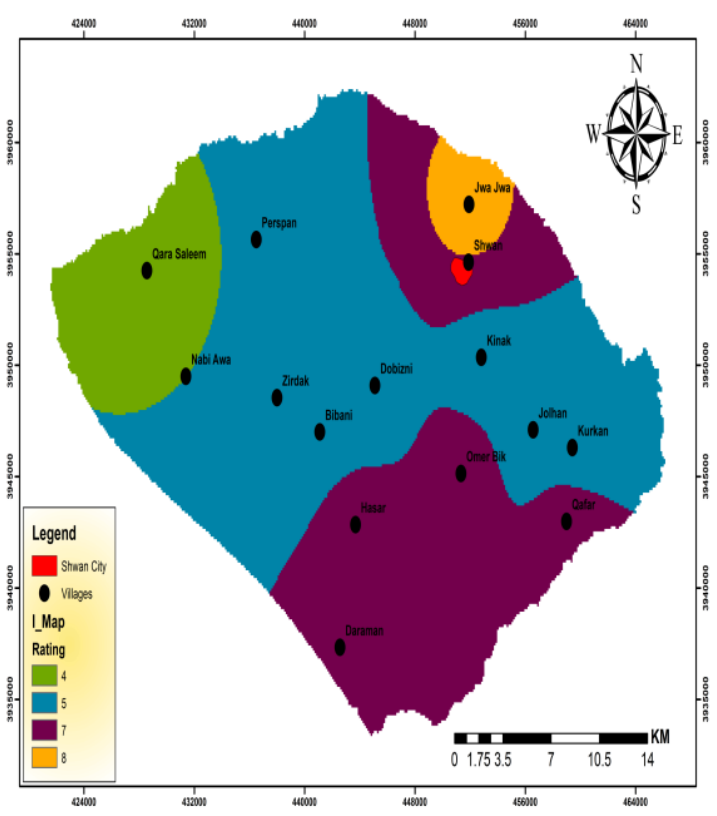

Figure 10- Rating map of impact vadose zone 


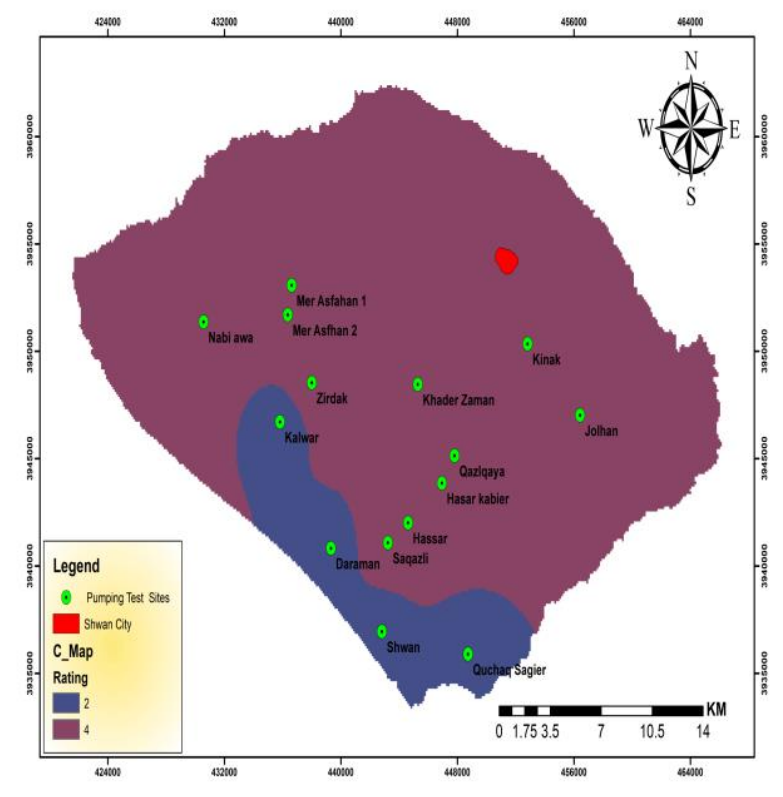

Figure 11- Rating map of hydraulic conductivity Shwan Area

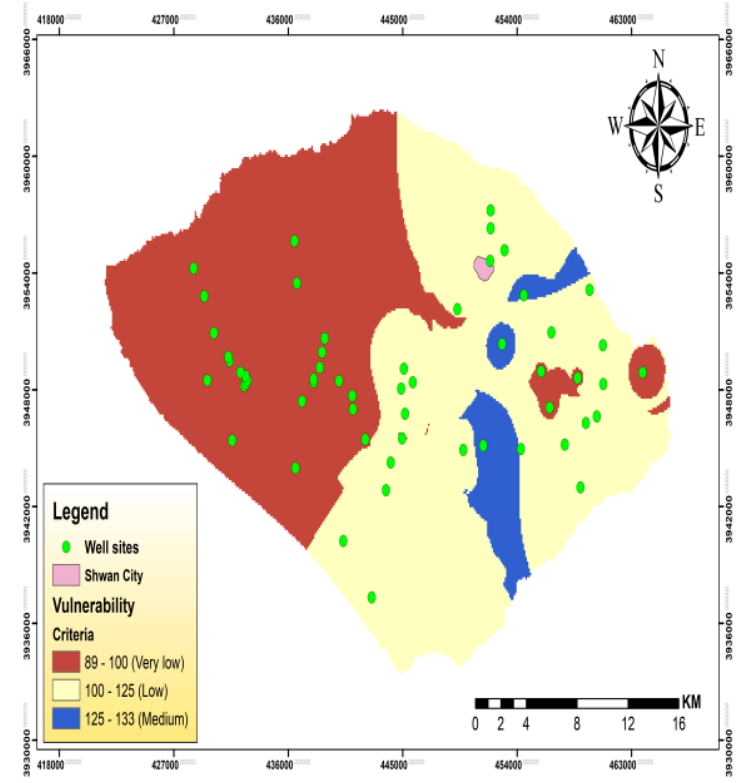

Figure 12- Groundwater vulnerability map of

\section{Conclusions}

The present study aimed to use the DRASTIC model for mapping the vulnerability of groundwater in Shwan sub-basin.

Generally, the results show that the range of vulnerability is low in most areas of the basin. The reason for the low DRASTIC range within the area may be the great depth of the groundwater in most parts of the basin, lack of recharge to groundwater, in addition to the confined aquifer condition for most parts of the basin. Through the results obtained, most parts of the basin can be used naturally for agricultural and industrial purposes, except some areas in the south-eastern and eastern parts. These parts must be developed before their usage for such purposes because of their moderate values of vulnerability, which can cause pollution to groundwater if used excessively without treatment. Vulnerability maps of the area can provide valuable bases for groundwater management and land-use planning.

\section{REFERENCES}

1. Warren P. W. and Daly D. 1998. Mapping Groundwater Vulnerability, Geological Society Special Publication, London; No. 130.

2. Hamamin, D.F., Qadir, R.A., Ali, S.S., Bosch, A.P. 2017. Hazard and risk intensity maps for water-bearing units: a case study. Int. J. Environ. Sci. Technol. https://doi.org/10.1007/s13762017-1376-1.

3. Panagopoulos, G., Antonakos, A., Lambrakis, N. 2006. Optimization of DRASTIC model for groundwater vulnerability assessment, by the use of simple statistical methods and GIS. Hydrogeol J 14:894-911.

4. Rahman, A. 2008. A GIS based model for assessing groundwater vulnerability in shallow aquifer in Aligarh, India. Appl Geogr 28:32-53.

5. Dixon, B. 2009. A case study using support vector machines, neural networks and logistic regression in a GIS to identify wells contaminated with NO3-N. Hydrogeol J 17:1507-1520

6. Sadeghfam, S., Hassanzadeh Y., Nadiri, A.A., Zarghami, M. 2016. Localization of groundwater vulnerability assessment using catastrophe theory. Water Resour Manag 30(13):4585-4601

7. Baghapour, M.A., Nobandegani, A.F., Talebbeydokhti, N., Bagherzadeh, S., Nadiri, A.A., Gharakhani, M., Chitsazan, N. 2016. Optimization of DRASTIC method by artificial neural network, nitrate vulnerability index, and composite DRASTIC models to assess groundwater vulnerability for unconfined aquifer of Shiraz Plain, Iran. J Environ Health Sci Eng 14(1):13. 
8. Hamamin, D.F., Nadiri, A.A. 2018. Supervised committee fuzzy logic model to assess groundwater intrinsic vulnerability in multiple aquifer systems. Arabian J. Geosci. 2018 (11), 176. https://doi.org/10.1007/s12517-018-3517-3.

9. Nadiri, A.A., Aghdam, F.S., Khatibi, R., Moghaddam, A.A. 2018. The problem of identifying arsenic anomalies in the basin of Sahand dam through risk-based 'soft modelling'. Sci Total Environ 613:693-706.

10. Jilali, A., Yassine, Zarhloule., Michael, Georgiadis. 2014. Vulnerability mapping and risk of groundwater of the oasis of Figuig, Morocco: application of DRASTIC and AVI methods. Arabian Journal of Geosciences. Springer.

11. Margat, J. 1968. Vulnerabilite de nappes d eau souterraine a la pollution [Groundwater vulnerability to contamination]. Bases de al cartographie, (Doc.) 68 SGC 198 HYD, BRGM, Orleans, France.

12. Aller, L., Bennett, T., Lehr, JH., Petty, R.H, and Hackett G. 1987. DRASTIC: a standardized system for evaluating groundwater pollution potential using hydrogeologic setting. USEPA report 600/2-87/035, Robert S. Kerr Environmental Research Laboratory, Ada, Oklahoma, 622 p.

13. Foster, S. 1987. Fundamental concepts in aquifer vulnerability, pollution risk and protection strategy. In: Van Duijvenbooden W, Van Waegeningh HG (eds) Vulnerability of soil and groundwater to pollutants. Committee on Hydrological Research, The Hague, 69-86.

14. Jilali A., Yassine, Zarhloule., Michael Georgiadis. 2014. Vulnerability mapping and risk of groundwater of the oasis of Figuig, Morocco: application of DRASTIC and AVI methods. Arabian Journal of Geosciences. Springer.

15. Van Stempvoort D., Ewert L, and Wassenaar L. 1993 .Aquifer vulnerability index (AVI): a GIS compatible method for groundwater vulnerability mapping. Can Water Resource J 18:25-37.

16. Hamamin, D. F. 2018. Passive soil gas technique for investigating soil and groundwater plume emanating from volatile organic hydrocarbon at Bazian oil refinery site. Sci. Total Environ. 2018, 622, 1485-1498.https://doi.org/10.1016/j.scitotenv.2017.11.328.

17. Jassim, S.Z. and Goff, J.C. 2006. Geology of Iraq (first edition). Published by Dolin, Prague and Moravian Museum, Brno, Czech Republic, 341p.

18. Sissakian, V.K. 1992. The Geology of Kirkuk Quadrangle, sheet NI-38-2, scale 1: 250000. GEOSURV, Baghdad, Iraq.

19. Hamamin, D.F. 2011. Hydrogeological Assessment and Groundwater Vulnerability Map of Basara Basin, Sulaimani Governorate, Iraq, Kurdistan Region. (PhD Thesis). College of Science, University of Sulaimani, p. 174.

20. Askarimarnani, S. S., and Garry Willgoose . 2014. Using the DRASTIC Model for Determination of Groundwater Vulnerability in Shallow Aquifer in Broke, NSW, Australia.

21. Ersoy, A., Fatma Gültekin. 2013. DRASTIC-based methodology for assessing groundwater vulnerability in the Gümüşhacıköy and Merzifon basin (Amasya, Turkey). Earth Sci. Res. SJ. Vol. 17, No. 1.

22. Mohammed, Juma'a. K. 2019. Hydrogeological Study and Mathematical Model of Shwan Subbasin in Kirkuk / Northern East Iraq. M.Sc. thesis submitted to the College of Science. Unvi. Of Kirkuk. p113.

23. Nachtergaele, F.; van Velthuizen,H.;vanEngelen, V.; Fischer, G.; Jones, A.; Montanarella, L.; Petri, M.; Prieler, S.; Teixeira, E.; Shi, X. Harmonized World Soil Database (version1.2); ORNL.DAAC: Oak Ridge, TN, USA, 2012; pp.1-50. Available online: http;//daac.ornl.gov/cgibin/dsviewer.pl?ds_id= 1247(accessed on 27 February 2020).

24. Kumar Sathees., D. Thirumalaivasan., Nisha Radhakrishnan. 2013. GIS Based Assessment of Groundwater Vulnerability Using Drastic Model.

25. Al Sudani, H.A. 1998. Hydrogeological and hydrochemical properities for groundwater system at Jolack Wadi Basin. M.Sc. thesis submitted to the College of Science. Unvi. Of Baghdad. p120. 